Conclusion Combined MMA embolization and surgical evacuation in cSDH patients appears to be associated with decrease 30-day ED utilization compared to surgery alone.

Disclosures J. Catapano: None. C. Nguyen: None. V. Srinivasan: None. C. Rutledge: None. T. Cole: None. J. Baranoski: None. S. Elmasry: None. M. Lawton: None. A. Jadhav: None. A. Ducruet: None. F. Albuquerque: None.

\section{0-032 TREATMENT OUTCOMES FOR ARUBA ELIGIBLE BRAIN ARTERIOVENOUS MALFORMATIONS: A COMPARISON OF REAL WORLD DATA FROM THE NVQI-QOD AVM REGISTRY TO THE ARUBA TRIAL}

${ }^{1} \mathrm{~N}$ Moore ${ }^{*},{ }^{2} \mathrm{R}$ Abdalla, ${ }^{3} \mathrm{~T}$ Patterson, ${ }^{2} \mathrm{Y}$ Moazeni, ${ }^{1} \mathrm{P}$ Rasmussen, ${ }^{1} \mathrm{G}$ Toth, ${ }^{1} \mathrm{M}$ Bain, ${ }^{2} S$ Ansari, 's Hussain. 'Cerebrovascular Neurosurgery, Cleveland Clinic Foundation, Cleveland, $\mathrm{OH} ;{ }^{2}$ Endovascular Neuroradiology, Northwestern University, Chicago, IL; ${ }^{3}$ Cerebrovascular Center, Cleveland Clinic Foundation, Cleveland, $\mathrm{OH}$

\subsection{6/neurintsurg-2021-SNIS.32}

Introduction Since the publication of the ARUBA trial, interventional management of cerebral arteriovenous malformations has become an area of debate. Treatment practices may have changed based on data from this recent trial which suggested that the risk of AVM treatment is greater than medical management in unruptured AVMs. To assess the 'real world' experience with interventional AVM outcomes, we compared outcomes of ARUBA eligible patients from the NVQI-QOD registry database to the ARUBA trial results.

Methods In an IRB approved study, the NVQI-QOD AVM registry database was queried for treated patients between 2017 to present with the following inclusion criteria: age > 18 years, baseline mRS $>1$, unruptured AVMs. 174/364 patients were ARUBA eligible and were included in the analysis. Patients were divided into embolization alone, microsurgery with or without embolization, and gamma knife radiation therapy with or without embolization. Primary outcomes of ischemic/hemorrhagic stroke or death were analyzed with a mean follow up time of 5.8 months (range 1 to 128 months). Results A total of $14(8.0 \%)$ of patients that underwent any type of intervention suffered stroke or mortality. The risk of stroke or death was $6.8 \%$ (5 of 74) for microsurgery, $5.4 \%$ ( 2 of 37 ) for gamma knife, and 10.9\% (7 of 64) for embolization alone. Annual stroke or death rates for all treatments were $7.5 \%$ (13 of 174 ) at one year and $0.57 \%$ (1 of 174) at 2 years.

Conclusion ARUBA eligible patients from the NVQI-QOD registry demonstrate a significantly lower risk of stroke or death with intervention of $8.0 \%(\mathrm{~N}=174)$ compared to the $30.7 \%(\mathrm{~N}=114)$ ARUBA trial interventional risk, and is nearly equivalent to the ARUBA trial medical management risk of 10.1\% ( $\mathrm{N}=109)$ over 33 months.

Disclosures N. Moore: 1; C; SNIS Joe Niekro Research Grant. R. Abdalla: None. T. Patterson: None. Y. Moazeni: None. P. Rasmussen: 2; C; Blockade Medical, Covidien/Medtronic, Stryker Neurovascular, Perflow Medical. 4; C; Perflow Medical. G. Toth: None. M. Bain: 2; C; Stryker Neurovascular. S. Ansari: None. S. Hussain: 2; C; Pulsar Inc.

\section{0-033 INTRACRANIAL VCAM1 AT TIME OF MECHANICAL THROMBECTOMY PREDICTS ISCHEMIC STROKE SEVERITY}

${ }^{1} \mathrm{~B}$ Maglinger*, 'M Sands, 'f Frank, ${ }^{2} \mathrm{C}$ McLouth, ${ }^{3} \mathrm{~A}$ Trout, ${ }^{4} \mathrm{~J}$ Roberts, ${ }^{5} \mathrm{~S}$ Grupke, ${ }^{3} \mathrm{~J}$ Turchan-Cholewo, ${ }^{6} \mathrm{~A}$ Stowe, ${ }^{7} \mathrm{~J}$ Fraser, ${ }^{6} \mathrm{~K}$ Pennypacker. ${ }^{1}$ Department of Neurology, University of Kentucky, Lexington, $K Y_{;}{ }^{2}$ Department of Behavioral Science, University of Kentucky, Lexington, KY; ${ }^{3}$ Department of Neurology; Center for Advanced Translational Stroke Science, University of Kentucky, Lexington, KY; ${ }^{4}$ Department of Neurosurgery, Neuroscience, Center for Advanced Translational Stroke Science, University of Kentucky, Lexington, $K Y ;{ }^{5}$ Department of Neurosurgery and Neuroendovascular Surgery, Covenant Medical Center, Lubbock, TX; ${ }^{6}$ Department of Neurology, Neuroscience, Center for Advanced Translational Stroke Science, University of Kentucky, Lexington, $K Y_{i}$ ${ }^{7}$ Department of Neurology, Neurosurgery, Radiology, Neuroscience, University of Kentucky, Lexington, $K Y$

\subsection{6/neurintsurg-2021-SNIS.33}

Background Emergent Large Vessel Occlusion (ELVO) strokes are devastating ischemic vascular events for which novel treatment options are needed. Using Vascular Cell Adhesion Molecule 1 (VCAM1) as a prototype, the objective of this study was to identify proteomic biomarkers and network signaling functions that are potential therapeutic targets for adjuvant treatment for mechanical thrombectomy.

Methods The Blood And Clot Thrombectomy And Collaboration (BACTRAC) study is a continually enrolling tissue bank and registry from stroke patients undergoing mechanical thrombectomy. Plasma proteins from intracranial (distal to clot) and systemic arterial blood (carotid) from $\mathrm{N}=42$ subjects were analyzed by Olink Proteomics. Statistical analysis of plasma proteomics used independent sample t-tests, correlations, linear regression, and robust regression models to determine network signaling and predictors of clinical outcomes. Data and network analyses were performed using IBM SPSS Statistics, SAS v 9.4, and STRING V11.

Results Increased systemic $(\mathrm{p}<0.001)$ and intracranial $(p=0.013)$ levels of VCAM1 were associated with the presence of hypertension. Intracranial VCAM1 was positively correlated to both infarct volume $(\mathrm{p}=0.032 ; \mathrm{r}=0.34)$ and edema volume $(p=0.026 ; r=0.35)$. The $\% \Delta$ in NIHSS from admittance to discharge was found to be significantly correlated to both systemic $(\mathrm{p}=0.013 ; \mathrm{r}=-0.409)$ and intracranial $(\mathrm{p}=0.011 ; \mathrm{r}=-0.421)$ VCAM1 levels indicating elevated levels of systemic and intracranial VCAM1 are associated with reduced improvement of stroke severity based on NIHSS from admittance to discharge. STRING-generated analyses identified biologic functional descriptions as well as function-associated proteins from the predictive models of infarct and edema volume.

Conclusions The current study provides novel data on systemic and intracranial VCAM1 in relation to stroke comorbidities, stroke severity, functional outcomes, as well as the role VCAM1 plays in complex protein-protein signaling pathways. These data will allow future studies to develop predictive biomarkers and proteomic targets for drug development to improve our ability to treat a devastating pathology.

Disclosures B. Maglinger: None. M. Sands: None. J. Frank: None. C. McLouth: None. A. Trout: None. J. Roberts: None. S. Grupke: None. J. Turchan-Cholewo: None. A. Stowe: None. J. Fraser: None. K. Pennypacker: None. 